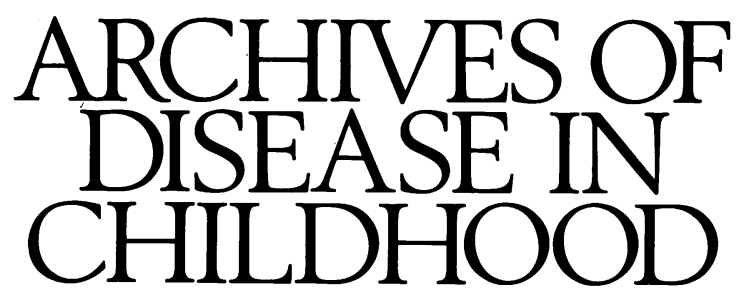

The fournal of the British Paediatric Association

\title{
Annotations
}

\section{Drug abuse in children and adolescents: an update}

Unlike cigarette smoking and alcohol drinking, there are no national surveys of drug abuse among children and adolescents in the UK. However, local small scale surveys and surveys of special populations from various parts of the UK indicate that $5-20 \%$ of school age children have 'ever tried' a drug with $2-5 \%$ using weekly or more often, and with a peak prevalence around the age of $14-16$ years. ${ }^{1}$ National American surveys usually report higher rates. Most dramatic in the USA is the increase in cocaine use: in 1985, over 1.1 million 12-17 year old adolescents had tried cocaine. ${ }^{2}$ However, recent reports suggest that there may be some decline. ${ }^{3}$ Overall about $5 \%$ of adolescent drug abusers in the USA meet the criteria for 'dependency', ${ }^{4}$ with multiple drug abuse being the rule rather than the exception. ${ }^{5}$

The age at which adolescents start drug taking is getting lower: an average of 13-15 years. Girls are less likely to use drugs and start later than boys. Once they start, however, their use is more committed. ${ }^{6}$ Earlier illicit drug abuse is often associated with heavier subsequent drug abuse, ${ }^{7}$ more persistent abuse, ${ }^{8}$ and the abuse of 'harder' drugs. ${ }^{9}$ Furthermore, starting to abuse illicit substances before the midteens is more likely to be associated with later delinquency, severe psychiatric disorders, and antisocial problems. ${ }^{7}$

Drug abuse is notoriously influenced by social and cultural factors such as social milieu, availability and legislation. Although adolescents can be involved in the abuse of any drug, they tend to be more involved in the abuse of volatile substances, cannabis, amphetamines, hallucinogenic substances, and 'pills' such as tranquilisers and hypnotics. Drug abuse is commonly associated with higher rates of alcohol use and cigarette smoking.

\section{Who is at risk?}

Drug abuse should now be suspected in preadolescents as well as adolescents. It can account for the physical manifestations and psychological disturbances seen in many youngsters. There are some children who should be perceived as being 'at higher risk' of drug abuse: children of substance abusers, victims of physical, sexual or emotional abuse, school drop outs, pregnant teenagers, economically disadvantaged children, delinquents, and those with mental health problems. ${ }^{4}$ Some 'relative risk factors' that would help in raising the level of suspicion of drug abuse were identified. ${ }^{10}$ The most significant indicator is peer drug abuse. However, other factors such as truancy, conflict with parents, law infringements, misbehaviour at school, alcohol use, and cigarette smoking are also indicative. The level of suspicion is directly related to the number of risk factors present.

\section{Psychopathology}

The relationship between psychopathology and drug abuse is very complex and still poorly understood, and the mechanism by which the two interact has not progressed much beyond establishing associations. The complex nature of psychopathology during adolescence poses an added difficulty in studies in this area. Longitudinal studies are necessary to unravel the picture.

Drug abuse in adolescence is commonly associated with inappropriate sexual behaviour, delinquency, school and social misbehaviour, and poor academic performance. ${ }^{11} 12$ Higher rates for psychosomatic complaints, anxiety, interpersonal conflict, social dysfunction, ${ }^{13}$ depressive symptoms, ${ }^{14}$ and suicide ${ }^{15}$ were reported among drug abusers. This led to the suggestion that drug abuse may, indeed, start as a form of self medication to relieve emotional distress. ${ }^{16}$ Swadi carried out a cluster analysis of 46 referred adolescent drug abusers and found that there were three groups. ${ }^{17}$ First, there was a behavioural dysfunction group making $76 \%$ of the sample, consisting mainly of boys, with an average age of 14 years with high rates of behavioural problems and adverse family dynamics. Almost half of them also showed depressive symptoms. Second was a family dysfunction group making $16 \%$ of the sample, consisting mainly of boys, with an average age of 13.5 years, and an abundance of adverse family dynamics. To a lesser extent, they also showed a mixture of emotional and behavioural symptoms. Third, was a life events/emotional dysfunction group making $8 \%$ of the sample, consisting mainly of 15-16 year old girls who showed high rates of significant and adverse life events. They showed significantly higher rates of emotional (especially depressive) than behavioural symptomatology. No adverse family dynamics were reported in this group.

\section{Physical manifestations}

Drug abuse can account for many physical manifestations in adolescents. A detailed account of the physical effects of specific substances is beyond the scope of this review and available elsewhere. ${ }^{18}$. However, drug abuse should be suspected when symptoms of sudden psychological change or deterioration of physical health are encountered, especially in particular groups of adolescents. ${ }^{4}$ Abuse of volatile 
substances accounts for about 100 deaths each year in the UK. ${ }^{19}$ Death usually results from anoxia, cardiac arrhythmias, respiratory depression, or trauma. Chronic abuse can cause symptoms of central nervous system depression, upper respiratory tract infections, persistent cough, and laryngitis and can cause cardiomyopathy, liver damage, or kidney damage. Stimulants such as amphetamines cause autonomic arousal, sleep disturbances, loss of weight, and in large doses, toxic confusional state. Cannabis often causes sweating, tachycardia, and peripheral vasodilatation. Opiates cause constipation, clouding of consciousness, nausea and vomiting, respiratory depression, and bradycardia. Some substances such as amphetamines and cannabis can cause toxic psychotic states, indistinguishable from schizophrenia.

The physical manifestations of a withdrawal syndrome are uncommon in adolescents because the syndrome of drug dependence itself is uncommon. If they occur, withdrawal symptoms depend on the type of substance abused. For example, gastrointestinal and 'flu'-like symptoms occur in opiate withdrawal; central nervous system excitability and even convulsions in barbiturate withdrawal; and lethargy, depression, and poor concentration in stimulants withdrawal. Cocaine withdrawal causes psychological rather than physical symptoms.

\section{Course and outcome}

The majority of adult 'addicts' start in their teens, ${ }^{20}$ but it is not yet possible to describe the 'course' of adolescent drug abuse accurately, Only a small proportion 'progress' to addiction. A natural 'maturational process' was suggested as a most likely outcome for most adolescent abusers. ${ }^{21}$ Those who do not 'mature out' would eventually form the core of future adult addicts. However, it is not yet possible to predict with confidence who would mature out. Some suggest that a conventional social role and a social context unfavourable to drugs predict early cessation. Furthermore, the degree of prior abuse and peer abuse of drugs are influential in future abuse. Those who abuse drugs for psychological reasons are less likely to stop than those who abuse for social reasons. ${ }^{21}$

Untreated, drug abusers are at risk of continued (possibly dangerous) use and high rates of psychiatric and social problems, ${ }^{22}$ with aggression, antisocial behaviour, occupational, and marital problems being most common. There is also the increased risk of HIV infection associated with the risky lifestyle drug abusing adolescents lead and the use of contaminated needles in some drug abusers. Adolescent drug abusers are more likely to have unprotected sexual intercourse after drug use. ${ }^{23}$

\section{Future directions}

Given the uncertainty about the course of drug abuse in adolescents, there has been a natural shift to put more emphasis on prevention. The 'epidemic' nature of drug abuse suggests that prevention should be both primary (prevention of initiation) and secondary (prevention of progression to more hazardous patterns and continuation into adulthood)

There is an increasing recognition that secondary prevention in the form of treatment is necessary. Current counselling services have a useful but inadequate role as there is much more to the treatment of drug abuse than counselling. Adult treatment services are by nature and design not suitable for adolescents. Special treatment facilities for adolescents have gone a long way in the USA but are virtually absent in the UK. There is a good case for special services given the extent of the problem and its specialist nature.

It is now well established that drug education, in many of its known forms, is ineffective with only very modest results at best. ${ }^{24}$ In view of the increasingly younger age of initiation into drug abuse, there is a strong case for introducing drug abuse prevention programmes at a younger age. That would require a rethink of prevention strategies with a move away from the didactic instructional methods currently employed and the adoption of a holistic approach towards the issue of health and behaviour in adolescents. Ideally, prevention should aim at total abstinence. However, as second best it may be useful to delay the onset of regular drug use as much as possible; this would spare the adolescent some of its worst effects in terms of more dangerous patterns of use and psychological and social adverse consequences.

Department of Child and Adolescent Psychiatry,

HARITH SWADI

United Medical and Dental Schools

of Guy's and St Thomas's Hospital,

St Thomas's Campus,

London SE $17 E H$

1 Institute for the Study of Drug Dependence. Drug missue in Britain. London: ISDD, 1990.

2 Brower K, Anglin M. Adolescent cocaine use: epidemiology, risk factors, and prevention. F Drug Educ 1987;17:163-80.

3 Anthony J. Epidemiology of drug dependence and illicit drug use. Current Opinion in Psychiatry 1991;4:435-9.

4 Bailey G. Current perspectives on substance abuse in youth. $7 \mathrm{Am}$ Acad Child Adolesc Psychiatry 1989;28:151-62.

5 Cohen S. The effects of combined, alcohol/drug abuse on human behaviour. In: Gardiner S, ed. Drug and alcohol abuse: implications for treatment. Rockville: Maryland National Institute on Drug Abuse, 1987:5-20.

6 Swadi $H$. Substance use among 3,333 London adolescents. Br f Addict 1988; 83:935-42.

7 Robins L, Helzer J, Przybeck T. Substance abuse in the general population. In: Barrett J, Rose R, eds. Mental disorders in the community: progress and challenges. New York: Guilford, 1986:9-29.

8 Kandel D, Raveis V. Cessation of illicit drug use in young adulthood. Arch Gen Psychiatry 1989;46:109-16.

9 Kandel D, Faust R. Sequence and stages in patterns of adolescent drug use. Arch Gen Psychiatry 1975;32:923-32.

$10 \mathrm{Swadi} \mathrm{H}$. Relative risk factors in detecting adolescent drug abuse. Drug Alcohol Depend 1992;29:253-4.

11 Fagan J, Weis J, Cheng Y. Delinquency and substance use among inner-city students. F Drug Issues 1990;20:351-402.

12 Hammersley $\mathrm{R}$, Forsyth Glassow. Br $\mathcal{F}$ Addict 1990;85:1583-94.

13 Lavik N, Onstad S. Drug use and psychiatric symptoms in adolescence. Acta Psychiatr Scand 1986;73:437-40.

14 Deykin E, Levy J, Wells V. Adolescent depression, alcohol and drug abuse. Am F Public Health 1987;77:178-82.

15 Fowler R, Rich C, Young D. San Diego suicide study: substance abuse in young cases. Arch Gen Psychiatry 1986;43:962-5.

16 Milin R, Halikas J, Meller J, Morse C. Psychopathology among substance abusing juvenile offenders. F Am Acad Child Adolesc Psychiatry 1991;30: $569-74$.

17 Swadi H. Clinical features of drug dependence. In: Seva A, ed. The European handbook of psychiatry and mental health. Barcelona: Anthropos, 1991: 1171-86.

18 Swadi H. Psychiatric symptoms in drug abusing adolescents. Drug Alcohol Depend 1992 (in press).

19 Ramsey $L$, Anderson $H$, Bloor $K$, Flanagan $R$. An introduction to the practice, prevalence and chemical toxicology of volatile substance abuse. practice, prevalence and chemical

20 Sheehan M, Oppenheimer E, Taylor $C$. Who comes for treatment: drug misuers at three London agencies. Br $\mathcal{F}$ Addict 1988;83:311-20.

21 Kandel D, Logan J. Patterns of drug use from adolescence to young adulthood: I. Period of risk for initiation, continued use and discontinuaadulthood: I. Period of risk for initiation,

22 Shedler J, Block J. Adolescent drug use and psychological health: a longitudinal enquiry. Am Psychol 1990;45:612-30.

23 Strunin L, Hingson R. Alcohol, drugs and adolescent sexual behaviour. Int $\mathcal{F}$ Addict 1992;27:129-46.

24 Swadi $\mathbf{H}$, Zeitlin $\mathbf{H}$. Drug education to school children: does it really work? $B r \mathcal{F}$ Addict 1987;82:741-6. 